\title{
A Novel ZCS/ZVS Bidirectional DC-DC Converter for Energy Storage Applications
}

\author{
V.V.Subrahmanya Kumar Bhajana ${ }^{1,2}$, Pavel Drabek ${ }^{2}$ \\ ${ }^{1}$ School of Electronics Engineering \\ KIIT University \\ Bhubaneswar, India \\ ${ }^{2}$ Regional Innovation Centre for Electrical Engineering \\ University of West Bohemia \\ Pilsen, Czech Republic \\ kumarbvv@rice.zcu.cz, bvvs.kumarfet@kiit.ac.in,drabek@ieee.org,drabek@kev.zcu.cz
}

\begin{abstract}
In this paper, a new soft-switched nonisolated bidirectional converter is proposed. This proposed converter is operated with soft-switching (zero current switching / zero voltage switching). It is implemented during the turn-on of main switching devices, with the addition of auxiliary resonant circuit that consists of an auxiliary switch, diode, capacitor and an inductor. The switching losses are significantly reduced due to soft-switching operation of the main switches. Therefore, the efficiency of this topology is improved. The additional benefit of this topology is that the auxiliary switches are also operated with softswitching. The proposed topology observes ZCS turn-on for boost mode and ZVS turn-on for buck mode operations. The principles of operation, design analysis and simulation verifications are discussed in detail. The soft-switching capabilities are obtained from design simulations on the $150 \mathrm{~V} / 250 \mathrm{~V} / 500 \mathrm{~W}$ converter system.
\end{abstract}

Keywords-Bidirectional DC-DC Converter; Auxiliary Resonant circuit; Soft-switching; Zero Voltage Switching; Zero Current Switching.

\section{INTRODUCTION}

In the past few decades non-isolated bidirectional converters are widely developed for the industrial applications such as hybrid electric vehicles, auxiliary power supplies, uninterruptable power supplies, renewable energy conversion systems and energy storages systems. In the battery energy storage system applications, bidirectional converters [2] are used to interface ultra-capacitors as sources. In these, the switches are operated with zero voltage transition (ZVT) by utilizing two auxiliary switches and an inductor. Such converters suffer from a reverse recovery problem. To avoid such problem, an inductor is coupled negatively in the buck-boost converter [1]. Nevertheless, this converter has improved efficiency and main switching devices have an increased voltage stress due to coupled inductors. In order to reduce current ripples by the input inductor in a bidirectional converter [3], an auxiliary winding to the input inductor and an additional inductor are included. Ripple free current and soft-switching techniques give better efficiency by reducing switching losses in a bidirectional converter [4] which has a simple structure and consists of a small inductor and two capacitors. The efficiency and volumes are the key parameters in designing converters. To improve the efficiency and reduce the converter volume, a single core coupled inductors and auxiliary switches are included in a bidirectional converter [5]. This converter achieves high efficiency at low output power level when the main switches are operated with zero voltage transition (ZVT). The effectiveness of nonisolated converters [6-7] was improved by auxiliary resonant networks. The auxiliary resonant networks consists of two switches, two diodes, a capacitor and an inductor. In these converters, the soft-switching is achieved for both main and auxiliary switches and performance is improved over the conventional nonisolated converters. However, the number of auxiliary component count is increased and thus volume.

In order to achieve zero voltage switching (ZVS) and improved efficiency, two different bidirectional converters with an additional transformer were reported [8-9], in which the main and auxiliary switches are turned-on with ZVS. As a result, switching losses are reduced and it may increase volume. On the other hand, the high step-up/stepdown [10] and interleaved boost converters [11] are realized by integrating a built-in transformer and resonant pulse transformers. These converters can have a high gain, reduced voltage stresses and zero voltage zero current switching (ZVZCS).

The main purpose of this paper is to design a simple soft-switched non-isolated converter for power supply applications. The conventional bidirectional converter is modified with a single auxiliary switch, a resonant inductor and a resonant capacitor. In this converter, regardless of power transfer, the switches are turned-on with ZCS and ZVS in both the boost and buck modes respectively. This topology improves efficiency and reduces the auxiliary component count compared to the existing versions [6-7]. As a result, size and overall cost of the converter are reduced.

This paper is organized is as follows, section II describes the operation principles and design analysis is discussed in section III. The design simulation results are presented in section IV. 


\section{DESCRIPTION AND OPERATION PRINCIPLES}

Fig.1 shows the proposed ZVS bidirectional converter. This converter is comprises of two MOSFETs $S_{1}$ (buck mode switch) and $S_{2}$ (boost mode switch). The auxiliary resonant cell consists of auxiliary MOSFET $S_{a}$, bypass diode $D_{a}$, one resonant inductor $L_{a}$, and a resonant capacitor $C_{a}$. This converter when it is operated in boost mode, the $S_{l}$ is turned-on to transfer power flow. While converter operated in boost mode, the switch $S_{2}$ is in off state. Similarly, whereas converter is working in buck mode, the switch $S_{1}$ is turned-on to transfer the desired output power. Duration of buck mode, the switch $S_{2}$ is turned-off. In both the modes, the auxiliary resonant cell will be in active a very short duration prior to turn-on of the main switch $\left(S_{1}\right.$ or $\left.S_{2}\right)$.

The bypass diode $D_{a}$ conducts from $\mathrm{t}_{0}-\mathrm{t}_{4}$ intervals and remaining intervals it is in non-conducting state. The operation of boost mode is divided into six intervals with in a switching period is as illustrated in Fig. 4 and equivalent operating modes shown in Fig.5

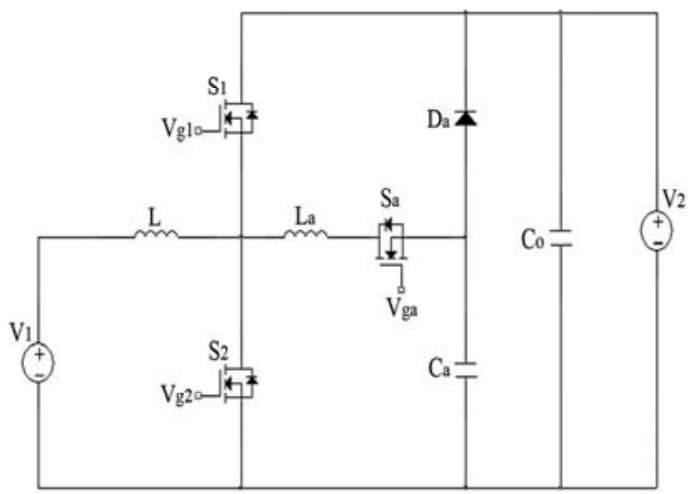

Figure 1. Proposed ZCS/ZVS Bidirectional DC-DC Converter

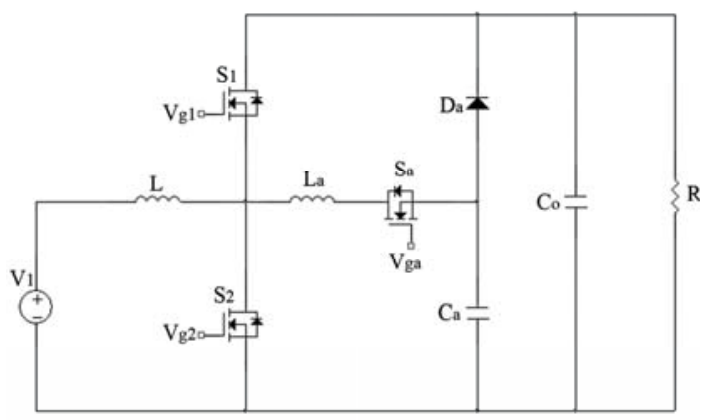

Figure 2. Equivalent circuit : Boost mode

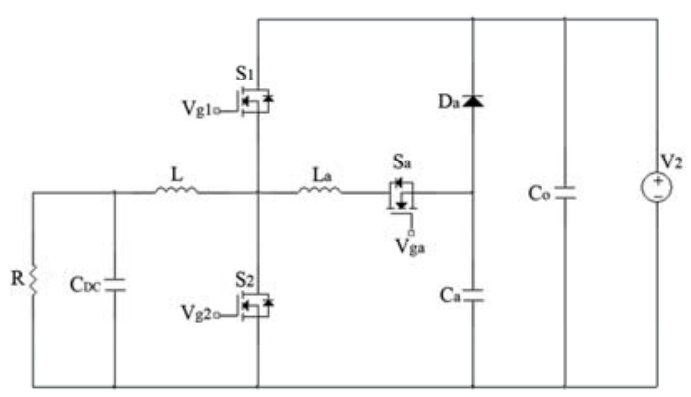

Figure 3. Equivalent circuit : Buck mode

\section{A. Boost mode}

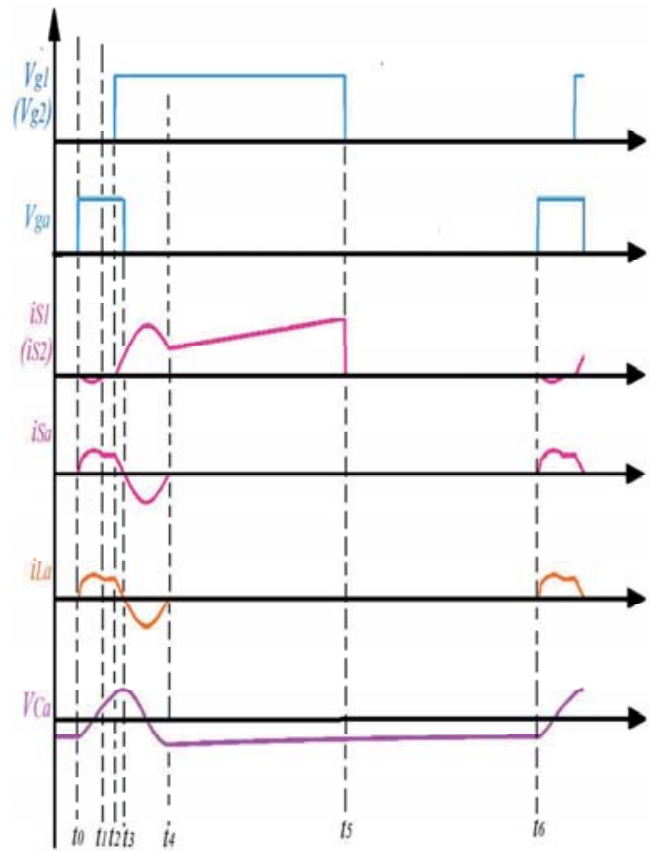

Figure 4. Keywaveform : Boost mode

Interval $\left(t_{0}-t_{1}\right)$ : At $t_{0}$, the auxiliary switch $S_{a}$ is turned on , then inductor current $i_{L a}$ linearly decreasing and capacitor $C_{a}$ is started discharging. Due to this resonant affect, the diode of $S_{2}$ gets forward biased and allows the tank current in to it. During half cycle of this interval, the $C_{a}$ is discharged and then started to charge. At time $t_{1}$, the diode of $S_{2}$ is stops conducting. The $V_{C a}$ and $I_{L a}$ are expressed as follows:

$$
\begin{aligned}
& \sqrt{\frac{L_{a}}{C_{a}}} i_{L a}(t)=-V_{\text {in }}(\sin \omega t)+\sqrt{\frac{L_{a}}{C_{a}}} I_{o} \\
& V_{C a}(t)=V_{i n}(1+\cos \omega t)
\end{aligned}
$$

$$
\text { Where } \omega=\frac{1}{\sqrt{L_{a} C_{a}}}
$$

Interval $\left(t_{1}-t_{2}\right)$ : This interval starts when current through the switch $S_{2}$ is reached zero. Thereby, the ZCS turn-on commutation achieved for $S_{2}$. The inductor current $i_{L a}$ is at constant, which equals to input current. At the end of this interval, the capacitor $C_{a}$ is completely charged to $-V_{l}$ and $S_{2}$ is turned-on.

Interval $\left(\mathrm{t}_{2}-\mathrm{t}_{3}\right)$ : This intervals begins at the $S_{2}$ is turned-on and its current increasing gradually from zero. The current through $L_{a}$ and voltage across $C_{a}$ are linearly increase by a slope of $\mathrm{V}_{1} / \mathrm{L}_{\mathrm{a}}$. At time $\mathrm{t}_{3}$, the current through the $S_{a}$ is reached zero. Therefore, the $S_{a}$ is achieved ZCS turn-off commutation. The expression for $L_{a}$ is as follows:

$$
i_{L a}(t)=\frac{V_{i n}}{L_{a}}
$$




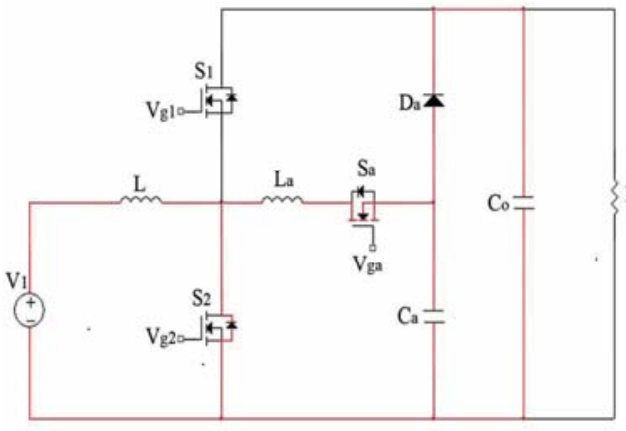

(a)

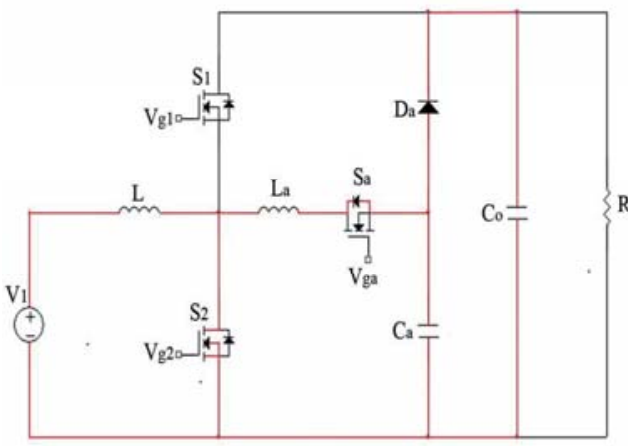

(c)

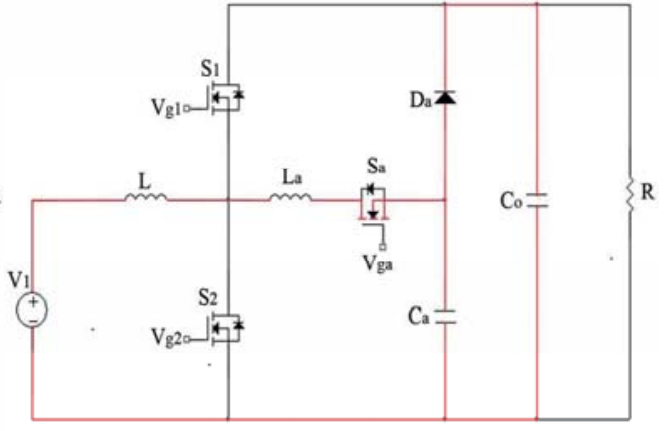

(b)

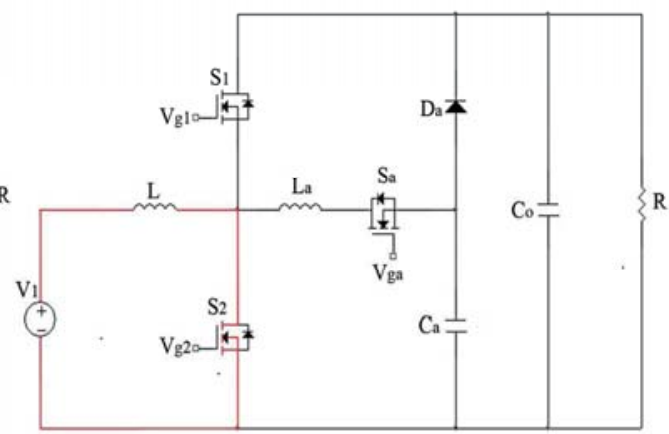

(d)

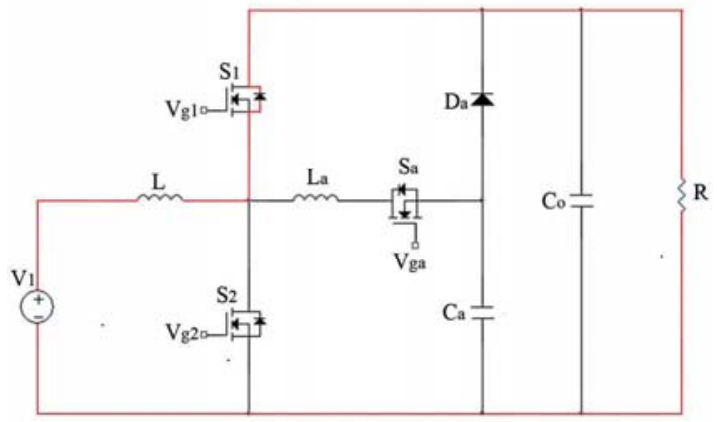

(e)

Figure 5. Operating modes : Boost mode (a) Interval $\left(t_{0}-t_{1}\right)(b)$ Interval $\left(t_{1}-t_{2}\right)(c)$ Interval $\left(t_{2}-t_{3}\right) \&$ Interval $\left(t_{3}-t_{4}\right)$ (d) Interval $\left(\mathrm{t}_{4}-\mathrm{t}_{5}\right)(\mathrm{e})$ Interval $\left(\mathrm{t}_{5}-\mathrm{t}_{6}\right)$

Interval $\left(\mathrm{t}_{3}-\mathrm{t}_{4}\right)$ : At time $\mathrm{t}_{3}$, the diode of $S_{a}$ is starts conducting and it will allow resonant tank current. At $\mathrm{t}_{4}$, the diode of $S_{a}$ is stops conducting. The $L_{a}$ current and voltage across $V_{C a}$ capacitor are linearly decreases as follows:

$$
\begin{aligned}
& \sqrt{\frac{L_{a}}{C_{a}}} i_{L a}(t)=V_{i n} \sin \omega t+\sqrt{\frac{L_{a}}{C_{a}}} I_{o} \\
& V_{C a}(t)=V_{i n}(1-\cos \omega t)
\end{aligned}
$$

Interval ( $\left.\mathrm{t}_{4}-\mathrm{t}_{5}\right)$ : At $\mathrm{t}_{4}, S_{2}$ is being in conducting state and throughout this interval the inductor $L_{d c}$ energy gets accumulated via $V_{l}-L-S_{2}$.

Interval $\left(\mathrm{t}_{5}-\mathrm{t}_{6}\right)$ : At time $\mathrm{t}_{6}$, the switch $S_{2}$ is turned off and the output current transferred by energy accumulated by $L$ via $V_{1}$ - $L$-diode of $S_{1}-R$.

\section{B. Buck mode}

The operation of buck mode is described five intervals from $t_{0}-t_{5}$ as shown in Fig.6 and Its operation current flow schematics shown in Fig.7.

Interval $\left(\mathrm{t}_{0}-\mathrm{t}_{1}\right)$ : At $\mathrm{t}_{0}$, the auxiliary switch $S_{1}$ is turned on at ZCS condition. Prior to this interval, the resonant capacitor $C_{a}$ is charged to $-V_{d c}\left(V_{2}\right)$ and resonant inductor current is at zero. The current through $L_{a}$ and voltage across $C_{a}$ are expressed as below:

$$
\begin{aligned}
& i_{L a}(t)=\frac{V_{C a}}{L_{a}}\left(t-t_{1}\right) \\
& V_{C a}(t)=V_{i n}(1+\cos \omega t)
\end{aligned}
$$

Interval $\left(\mathrm{t}_{1}-\mathrm{t}_{2}\right)$ : This is a very short time interval, at $\mathrm{t}_{1}$, the auxiliary switch $S_{a}$ is turned off and its current reached zero. Due to resonance, the resonant tank current will flows through the body diodes of the main switch $S_{l}$ and $S_{a}$. Since the voltage of switch $S_{I}$ is 
zero before the gate pulse of $S_{1}$ is applied, the ZVS operation is achieved.

$$
i_{L a}(t)=I_{o}-\frac{V_{o}-V_{C a}}{L_{a}}\left(t-t_{2}\right)
$$

Interval $\left(\mathrm{t}_{3}-\mathrm{t}_{4}\right)$ : Throughout this interval, the output power transfer via $V_{2}-S_{1}-L-R$.

Interval $\left(t_{4}-t_{5}\right)$ : During this mode, there is no output power will be delivered.

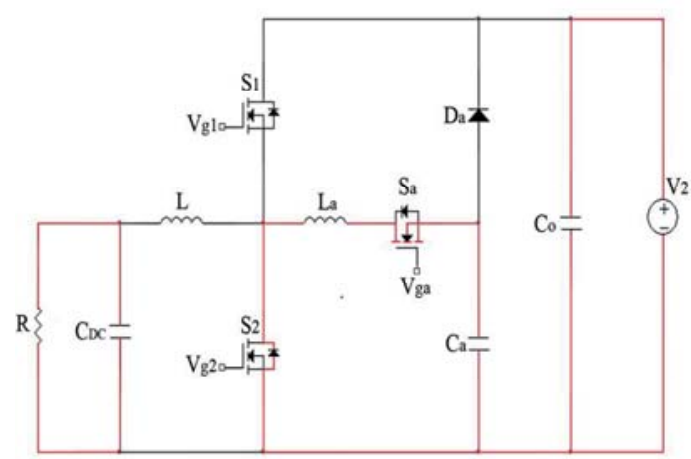

(a)

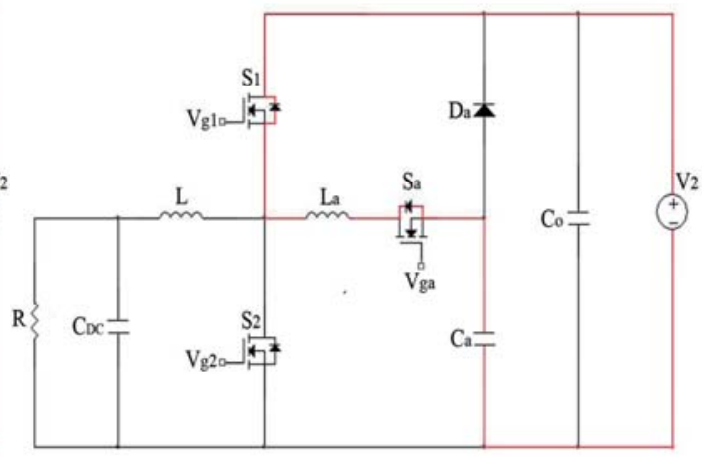

(b)

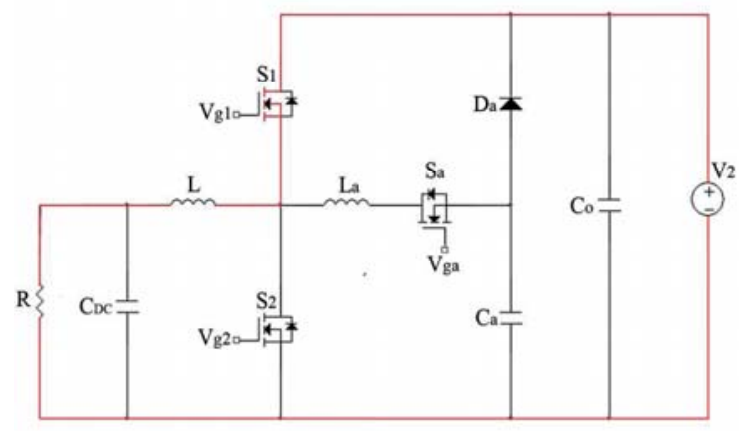

(c)

Figure.7 Operating modes: Buck mode (a) Interval ( $\left.t_{0}-t_{1}\right)$ (b) Interval ( $\left.t_{1}-t_{2}\right)$ (c) Interval $\left(t_{2}-t_{3}\right) \&\left(t_{3}-t_{4}\right)$

Interval $\left(\mathrm{t}_{2}-\mathrm{t}_{3}\right)$ : At $\mathrm{t}_{2}$, the $S_{1}$ is turned on. The inductor $L_{a}$ current reached zero and $C_{a}$ is completely charged to $+V_{d c}\left(+V_{2}\right)$.

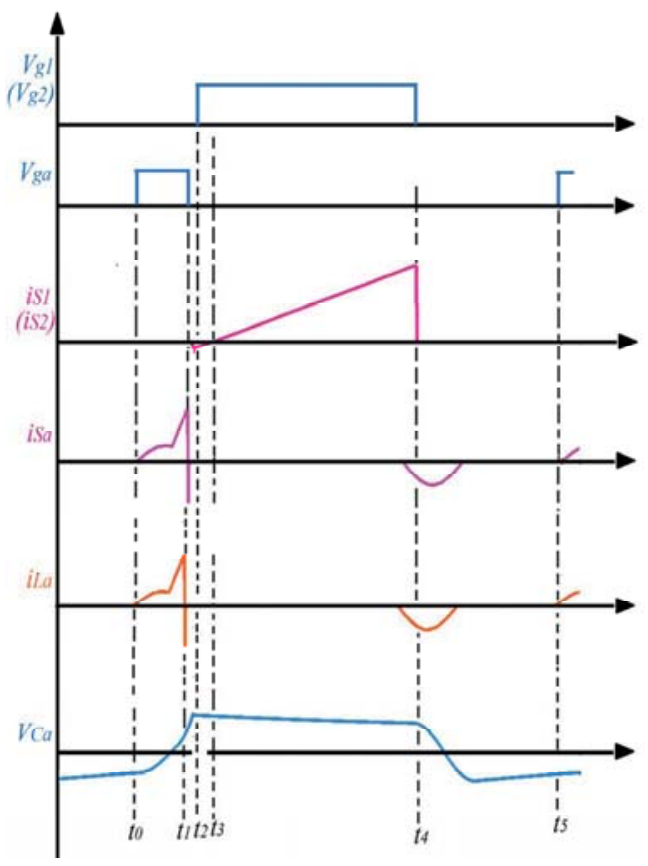

Figure 6. Keywaveform : Buck mode

\section{ZERO CURRENT SWITCHING AND ZERO VOLTAGE SWITCHING CONDITIONS}

The soft-switching turn on conditions ZCS and ZVS are obtained only when the following condition is satisfied.

$$
k<1
$$

Where $k=\frac{I_{\max }}{V_{i \min }} \sqrt{\frac{L_{a}}{C_{a}}} ; I_{\max }=\frac{P_{\max }}{V_{o}}$

The parameters $L_{a}$ and $C_{a}$ of resonant circuit are given by equations (10) and (11).

$$
\begin{aligned}
& L_{a} C_{a}=\frac{1}{\left(2 \pi f_{r}\right)^{2}} \\
& \frac{L_{a}}{C_{a}}=\left(\frac{V_{i \min } k}{I_{\max }}\right)^{2}
\end{aligned}
$$

\section{Simulation Results}

In order to verify the performance of proposed topology, the design simulations were performed on Matlab Simulink. The converter design parameters are mentioned as Table I. The simulations are performed for both the boost and buck modes separately. Fig. 8 shows the current and voltage waveforms of $S_{2}, S_{a}$. It can be seen from the simulation results, the softswitching operation was achieved for main switch $S_{2}$ 
and $S_{a}$ as theoretical expectations.As it is observed, the ZCS turn on operation obtained for main switch $S_{2}$ and auxiliary switch $S_{a}$ is turned on at ZCS and turned off at ZCS. Hence, this proposed converter operated in boost mode, the turn-on switching losses are reduced and there are no additional losses by auxiliary circuit. Fig. 9 shows the $L_{a}$ current and $C_{a}$ voltage waveforms. The peak current through $L_{a}$ is $2 \mathrm{~A}$ and $C_{a}$ is charged and discharged to the level of input voltage i.e $150 \mathrm{~V}$. Fig. 10 shows voltage and current waveforms of $S_{l}$ and $S_{a}$ for buck mode of operation. The currents through $S_{l}$ are $5.7 \mathrm{~A}$ and $S_{a}$ is $0.5 \mathrm{~A}$. There is a turn off current peak across $S_{a}$ is observed. It can be seen that, the zero voltage switching turn on achieved for $S_{l}$. It is also observed that the $S_{a}$ is obtained ZCS turn on and ZCS turn off. Fig. 11 shows the $L_{a}$ current and $C_{a}$ voltage waveforms. The peak current through the $L_{a}$ is $0.5 \mathrm{~A}$. The resonant capacitor $C_{a}$ is charged and discharged to the level of $10 \mathrm{~V}$. Fig.11 shows the zero current switching turn-on transition to the switches $S_{2}$ and $S_{a}$ for boost mode. Fig.12 depicts the zero voltage switching and zero current switching transitions for the $S_{l}$ and $S_{a}$ for buck mode.

TABLE I. SIMULATION PARAMETERS

\begin{tabular}{|l|c|c|}
\hline Parameter & Symbol & Value \\
\hline Input voltage & $V_{I}$ & $150 \mathrm{~V}$ \\
\hline $\begin{array}{l}\text { Ouput } \\
\text { voltage }\end{array}$ & $V_{o}\left(V_{2}\right)$ & $250 \mathrm{~V}$ \\
\hline $\begin{array}{l}\text { Switching } \\
\text { frequency }\end{array}$ & $f_{s}$ & $50 \mathrm{kHz}$ \\
\hline $\begin{array}{l}\text { Input } \\
\text { inductor }\end{array}$ & $L$ & $100 \mu \mathrm{H}$ \\
\hline $\begin{array}{l}\text { Resonant } \\
\text { Inductor }\end{array}$ & $L_{a}$ & $20 \mu \mathrm{H}$ \\
\hline $\begin{array}{l}\text { Resonant } \\
\text { Capactitor }\end{array}$ & $C_{a}$ & $40 \mathrm{nF}$ \\
\hline $\begin{array}{l}\text { Output } \\
\text { capacitor }\end{array}$ & $C_{o}$ & $470 \mu \mathrm{F}$ \\
\hline
\end{tabular}
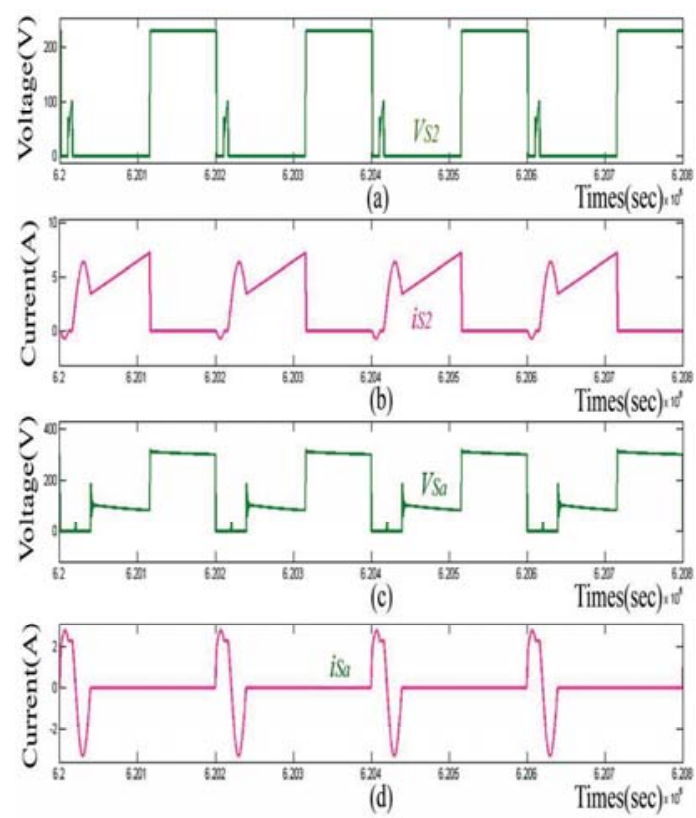

Figure 8. Voltage and Current waveforms of $S_{2}$ and $S_{a}$ : Boost mode (a) $V_{S 2}$ (b) $i_{S 2}$ (c) $V_{S a}$ (d) $i_{S a}$
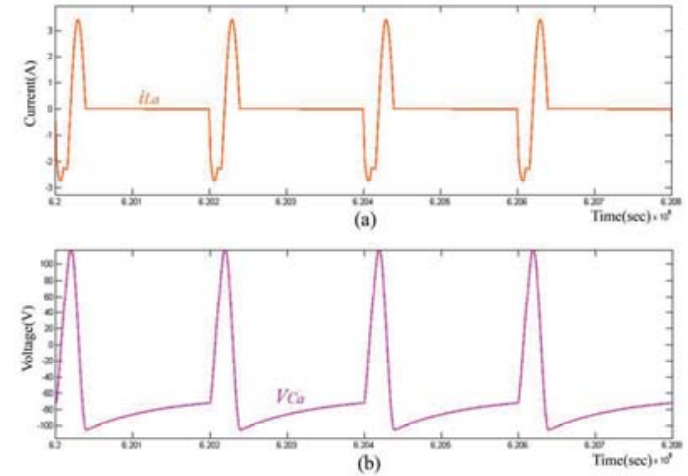

Figure 9. Resonant inductor $L_{a}$ current and $C_{a}$ voltage waveforms : Boost mode : (a) $i_{L a}$ (b) $V_{C a}$
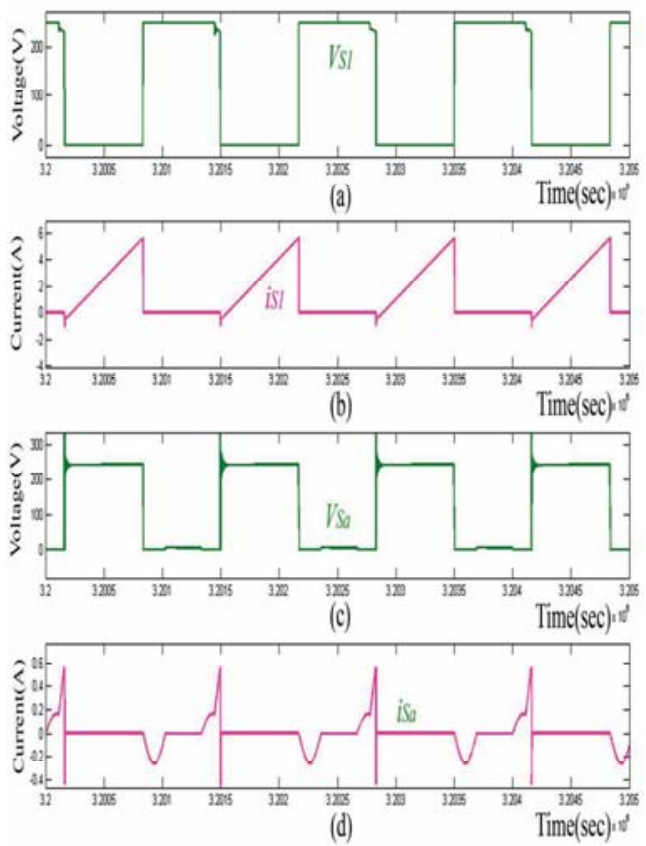

Figure 10. Voltage and current waveforms of $S_{l}$ and $S_{a}$ : Buck mode (a) $V_{S I}$ (b) $i_{S I}$ (c) $V_{S a}$ (d) $i_{S a}$
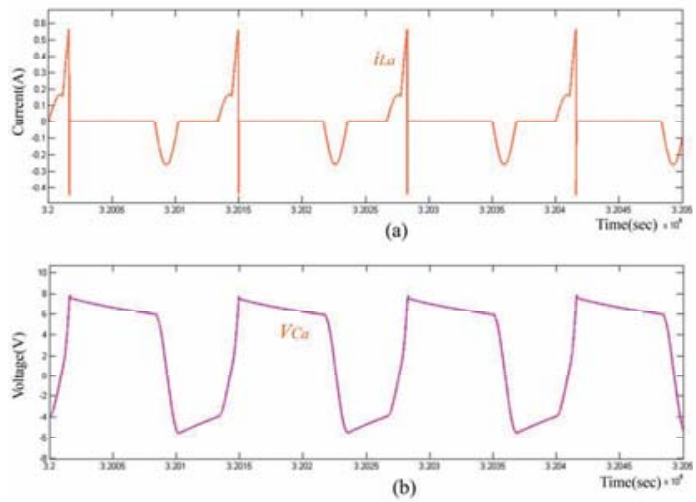

Figure 11. Resonant inductor $L_{a}$ current and $C_{a}$ voltage waveforms : Buck mode (a) $i_{L a}$ (b) $V_{C a}$ 

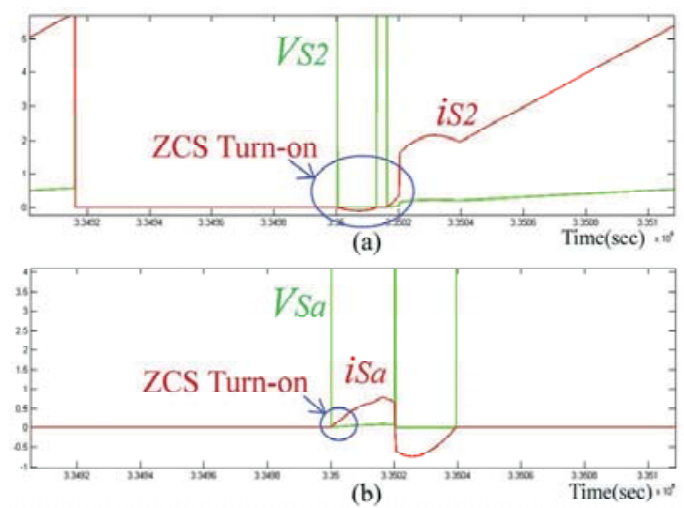

Figure 12. ZCS Turn-on Transition (a) $V_{S 2} \& i_{S 2}$ (b) $V_{S a} \& i_{S a}$ : Boost mode

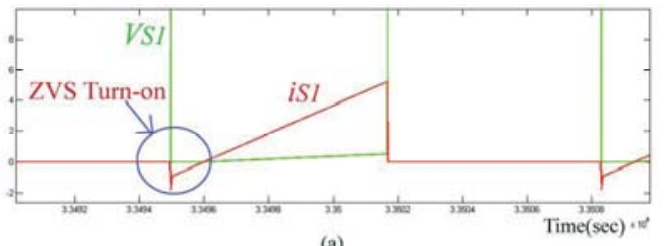

(a)

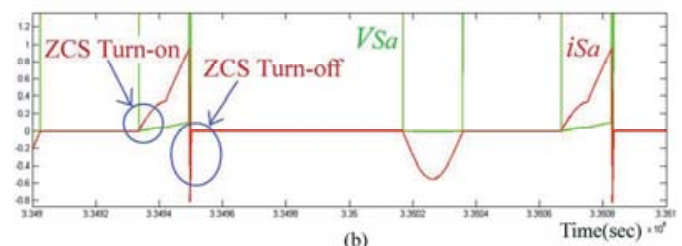

Figure 13 (a). ZVS Turn-on Transition $V_{S 2} \& i_{S 2}$ (b) ZCS Turn-on and Turn-off transition $V_{S a} \& i_{S a}$ : Buck mode

\section{CONCLUSION}

This paper proposes a new soft-switching nonisolated bidirectional converter for energy storage applications. The operating principles and simulations are discussed in detail. The proposed topology operates with $150 \mathrm{~V}$ as input and $250 \mathrm{~V}$ at $500 \mathrm{~W}$ output power. While converter operates in boost mode, the zero current switching turn on operation is achieved on the main switch and on auxiliary switch as well. Similarly, in buck mode, the main switch is turned-on with ZVS and auxiliary switch is turned-on with ZCS. In addition to these ZCS/ZVS operations, the auxiliary circuit, which is used in this topology, is with less number of components as compared with existing versions. It also reduces turn on losses and improves efficiency. This paper provides simulation analysis of the converter, which lays foundation to evaluate it experimentally. It introduces an efficient structure for energy storage applications and in future, the same can be used for wide band gap semiconductor devices such as $\mathrm{SiC}, \mathrm{GaN}$.

\section{ACKNOWLEDGMENT}

This research has been supported by Technology Agency of the Czech Republic (TACR) No. TE01020038: Centre of Competence of Railway Vehicles.

\section{REFERENCES}

[1] H. Wu, J. Lu, W. Shi and Y. Xing, "Nonisolated Bidirectional DC-DC Converters With Negative-Coupled Inductor," IEEE Transactions on Power Electronics, vol. 27, no. 5, pp. 22312235, May 2012.

[2] H. Farzaneh-fard, D. S. Beyragh and E. Adib, "A Fully Soft Switched Converter for Ultracapacitors Interface Circuit," 2006 IEEE International Conference on Industrial Technology, Mumbai, 2006, pp. 796-800.

[3] H. Do, "Nonisolated Bidirectional Zero-Voltage-Switching DC-DC Converter," IEEE Transactions on Power Electronics, vol. 26, no. 9, pp. 2563-2569, Sept. 2011.

[4] Y. Zhang, X. Cheng, C. Yin and S. Cheng, "Analysis and Research of a Soft-Switching Bidirectional DC-DC Converter Without Auxiliary Switches," IEEE Transactions on Industrial Electronics, vol. 65, no. 2, pp. 1196-1204, Feb. 2018.

[5] M. R. Mohammadi and H. Farzanehfard, "New Family of Zero-Voltage-Transition PWM Bidirectional Converters With Coupled Inductors," IEEE Transactions on Industrial Electronics, vol. 59, no. 2, pp. 912-919, Feb. 2012.

[6] S. Oh, J. Kim, J. Kim, C. Won and Y. Jung, "The analysis of a novel bidirectional soft switching DC-DC converter," 8th International Conference on Power Electronics - ECCE Asia, Jeju, 2011, pp. 2154-2159.

[7] J. Yang and H. Do, "Soft-Switching Bidirectional DC-DC Converter Using a Lossless Active Snubber," IEEE Transactions on Circuits and Systems I: Regular Papers, vol. 61, no. 5, pp. 1588-1596, May 2014.

[8] G. Chen et al., "A Family of Zero-Voltage-Switching Magnetic Coupling Nonisolated Bidirectional DC-DC Converters," IEEE Transactions on Industrial Electronics, vol. 64, no. 8, pp. 6223-6233, Aug. 2017.

[9] Y. Jang and M. M. Jovanović, "Soft-switched bidirectional buck-boost converters," IEEE Applied Power Electronics Conference and Exposition (APEC), Tampa, FL, 2017, pp. 287-293.

[10] H. Wu, Y. Lu, L. Chen, P. Xu, X. Xiao and Y. Xing, "High step-up/step-down non-isolated BDC with built-in DCtransformer for energy storage systems," IET Power Electronics, vol. 9, no. 13, pp. 2571-2579, 2016.

[11] M. R. Ahmed, R. Todd and A. J. Forsyth, "Soft-switching operation of the dual-interleaved boost converter over all duty ratios," IET Power Electronics, vol. 10, no. 11, pp. 12501258, 2017. 